\title{
Spatial Navigation: Implications for Animal Models, Drug Development and Human Studies
}

\author{
A. STUCHLIK ${ }^{1}$, S. KUBIK ${ }^{1}$, K. VLCEK $^{1}$, K. VALES $^{1}$ \\ ${ }^{1}$ Department of Neurophysiology of Memory, Institute of Physiology Academy of Sciences of the \\ Czech Republic, Prague, Czech Republic
}

Received August 13, 2013

Accepted September 16, 2013

\begin{abstract}
Summary
Spatial navigation and memory is considered to be a part of the declarative memory system and it is widely used as an animal model of human declarative memory. However, spatial tests typically involve only static settings, despite the dynamic nature of the real world. Animals, as well as people constantly need to interact with moving objects, other subjects or even with entire moving environments (flowing water, running stairway). Therefore, we design novel spatial tests in dynamic environments to study brain mechanisms of spatial processing in more natural settings with an interdisciplinary approach including neuropharmacology. We also translate data from neuropharmacological studies and animal models into development of novel therapeutic approaches to neuropsychiatric disorders and more sensitive screening tests for impairments of memory, thought, and behavior.
\end{abstract}

\section{Key words}

Memory • Learning • Navigation • Spatial representation • Moving environments $\bullet$ Rats $\bullet$ Animal models $\bullet$ Brain $\bullet$ Neurons

\section{Corresponding author}

A. Stuchlik, Institute of Physiology, Academy of Sciences of the Czech Republic, Videnska 1083, 14220, Prague, Czech Republic. Fax: +420241062488. E-mail: stuchlik@biomed.cas.cz

\section{Introduction to spatial memory}

Spatial (place) navigation of rats is one of the most popular behavioral models to examine neurobiological mechanisms underlying learning and memory, decision-making, and other higher cognitive processes (O'Keefe and Nadel 1978). The advantages of spatial tasks arise at many points: navigation is natural for most species, thus facilitating comparative studies (Nekovarova et al. 2013). The available sensory information can be controlled (Blahna et al. 2011) and navigational tests can be combined with advanced inactivation, electrophysiological, or molecular techniques to see how the brain processes information and gives rise to behavioral actions. Moreover, place navigation constitutes an animal model of human declarative memory (Eichenbaum 2001) or a distinct subcomponent of declarative memory (Morris 2013).

In dynamic, real-world settings, both animals and humans often have to interact with moving objects or even whole moving environments. Spatial navigation, especially in such dynamic environments, involves time perception (interval timing; Buhusi and Meck 2005), giving rise to timing strategies and their combinations with place responses (Klement et al. 2010). In addition to representations of hidden goals (Morris 1984), recognition of positions of objects in a directly inaccessible space (Klement et al. 2010, Levcik et al. 2013), continuous updating of changing information (Morris and Frey 1997) such as during navigation by visible, but continuously moving objects (Telensky et al. 2009, 2011, Svoboda et al. 2012), behavioral flexibility (Burghardt et al. 2012), and cognitive coordination of multiple information streams (Wesierska et al. 2005, Kubik and Fenton 2005) are important components of navigation in dynamic environments. Together, these processes give rise to highly flexible and purposeful spatial behavior based on internal representations of the 
environments in the form of "cognitive maps" (Tolman 1948).

\section{Brain structures participating in spatial memory}

The hippocampus is connected in a wider functional network of the hippocampal formation consisting of the hippocampus proper (Cornu Ammonis; CA1-4), the dentate gyrus, and the subicular complex (Amaral and Witter 1989). Together with the neighboring entorhinal, perirhinal, and postrhinal cortical areas it is often, especially in human literature, referred to as the medial temporal lobe system (Eichenbaum 2001). The role of the hippocampus in memory has been acknowledged since the seminal report about Henry Gustav Molaison (formerly known as famous patient H. M.), who suffered profound anterograde amnesia of declarative memory after resection of large portions of medial temporal lobes including the hippocampus as a therapy for pharmacoresistant temporal epilepsy (Scoville and Milner 1957). A more specific theory of hippocampal function proposes that it forms a "cognitive map" of the environment, which is particularly useful when navigating to hidden goals, i.e. "place navigation" (Tolman 1948, O'Keefe and Nadel 1978). This influential concept shaped decades of hippocampal studies in animals, although it has also been shown that the hippocampus plays a critical role in anxiety (especially its ventral part; Bannerman et al. 2004, Kheirbek et al. 2013), and in organizing multiple streams of information (cognitive coordination; Wesierska et al. 2005). The hippocampus is also crucial for recognizing familiar places even without any navigational demands (Klement et al. 2005) and for recognizing position of objects in inaccessible environment (Levcik et al. 2013). Recently, the hippocampus has been suggested to play a role in spatial choice rather than spatial knowledge (Bannerman et al. 2012), further underlining the role of neocortex.

Several neocortical areas interconnected with the hippocampus are involved in place navigation, including the piriform, perirhinal, and retrosplenial cortices. The retrosplenial cortex (RSC) lies at the "interface" between the hippocampus and neocortical associational areas and it may play a role in integration of egocentric and allocentric information streams (Byrne et al. 2007). Indeed, RSC dysfunction impairs navigation in dissociated ego- and allocentric spatial frames (Wesierska et al. 2009), pointing to its role in cognitive coordination.
Another area involved in navigation and spatial memory is the posterior parietal cortex, which is mainly responsible for egocentric processing (Whitlock et al. 2012, but see Svoboda et al. 2009). Importance of entorhinal cortex should also be emphasized, given the fact that it provides the main excitatory drive and information input into dentate gyrus, considered a gateway to the hippocampus.

Importantly, neurons within the wider hippocampal network in rodents display a variety of spatially specific activity. Pyramidal neurons in the hippocampus behave as place cells, i.e. they increase their firing rate only when the animal visits a cell-specific place, called the firing-field (O'Keefe and Dostrovsky 1971). Other functional cell types include head direction cells (Taube et al. 1990) in the subiculum, RSC, and anterior thalamus, grid cells and border cells in the medial entorhinal cortex (Fyhn et al. 2004, Hafting et al. 2005) and cells with mixed head direction/place/velocity firing correlates in the RSC (Cho and Sharp 2001). Head direction cells respond when the subject's head is turned in a particular direction, whilst grid cells fire at multiple locations forming a periodic hexagonal grid covering the entire environment. Other cell types respond to spatial boundaries (border cells) or to combinations of spatial variables such as place, head direction, and velocity.

Importantly, the hippocampal formation, specifically the DG, is one of two sites of neurogenesis in the adult brain (Altman and Das 1965). Newly-born neurons in the dentate gyrus are proposed to facilitate learning in the hippocampus by separating overlapping patterns in hippocampal inputs, thus ensuring formation of distinct representations (Sahay et al. 2011, Nakashiba et al. 2012) and preventing interference of new memories with old ones (Wiskott et al. 2006, Winocur et al. 2011). Recently, their role has been reformulated to increase "memory resolution" so that cooperation between newlyborn, hyperexcitable granule cells and older neurons that code sparsely for salient features increases the amount of detail encoded in hippocampal memories (Aimone et al. 2011). Notably, the role of adult neurogenesis in the updating of dynamic environmental features is still controversial, despite recent demonstration of their involvement in behavioral flexibility in mice (Garthe et al. 2009, Burghardt et al. 2012).

Interestingly, many types of place navigation require the hippocampus or hippocampal formation in general and are disrupted in many brain disorders. We hypothesize that the hippocampus disruption may in fact 
be a "apparent link" between several serious brain disorders and cognitive deficits observed in these conditions (Fig. 1).

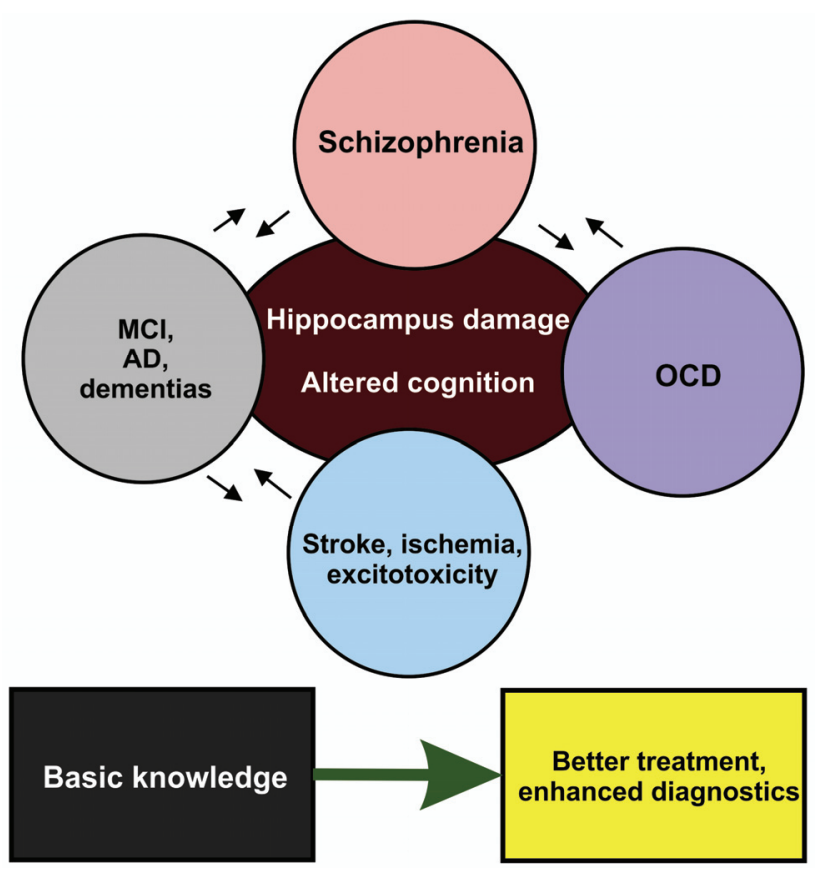

Fig. 1. Schematic illustration of mutual relation of neuropsychiatric disorders to the hippocampal alterations and behavioral and cognitive abnormalities. Our efforts go from understanding of basic processes in animal models to enhanced design and screening of drugs and neurodiagnostics (bottom of the figure). OCD: Obsessive-compulsive disorder, MCI: Mild cognitive impairment, AD: Alzheimer's disease.

Real world environments often involve multiple frames of reference, which continuously change their relationship. People as well as animals encounter environments consisting of a mixture of relevant and irrelevant information, which can be organized in multiple reference frames (e.g. idiothetic vs. allothetic, own position relative to conspecifics, family, rivals, prey, predators, and moving objects in an environment, vs. relative to the ambient space). Although the need to organize behavior in multiple frames of reference is a common challenge in everyday life, most tests of spatial memory and navigation occur in static environments or involve only one-off changes such as change in goal location or between-session alternations. In contrast, active place avoidance on Carousel (Stuchlik et al. 2012, 2013) challenges experimental subjects with two dissociated spatial reference frames of stationary room and rotating arena. They are required to avoid a hidden place defined in a stationary room on a continuously rotating circular arena (extensively reviewed in Stuchlik et al. 2013). This behavior critically depends on the hippocampus because inactivation of one hippocampus by injection of voltage-dependent $\mathrm{Na}^{+}$channel blocker tetrodotoxin completely abolishes the avoidance (Cimadevilla et al. 2001). Follow-up experiments revealed that soma variants of place avoidance on the Carousel depends on hippocampus-dependent cognitive coordination or cognitive control (Wesierska et al. 2005, Kubik and Fenton 2005, Kelemen and Fenton 2010) and that this function is distinct from hippocampal role in spatial memory as tested in a water maze (Kubik and Fenton 2005). These findings justify the use of the place avoidance task as a valuable model of a dynamic, realworld environment where multiple frames of reference continuously change their relationship in the study of neurobiology of cognition, cognitive disorders, and their potential therapies (Czéh et al. 2001, Stuchlik et al. 2004, 2007b, 2008, 2012, 2013, Kubik and Fenton 2005, Stuchlik and Vales 2005, 2006, 2008, Vales and Stuchlik 2005, Kubik et al. 2006, Petrasek and Stuchlik 2009, Vales et al. 2010, Entlerova et al. 2013, Lobellova et al. 2013, Zemanova et al. 2013).

\section{Schizophrenia and animal models}

Schizophrenia is a devastating disease affecting approximately $1 \%$ of world's population. It is one of the most serious neuropsychiatric disorders with enormous human, medicinal and socioeconomic impact. Its symptoms are typically denoted as positive (hallucinations, delusions, disorganization) and negative (social withdrawal, anhedonia, decreased psychomotor tempo). Schizophrenia is also characterized by stable and reproducible cognitive symptoms, as a typical thought disorder. The cognitive deficit is now perceived as primary and the most stable symptom of the disease. It is present before the full onset as well as in remission and also in first-degree relatives of schizophrenic patients, forming a stable and heritable endophenotype. Cognitive deficits in schizophrenia reach multiple domains, ranging from psychomotor functions, verbal fluency, sensorimotor gating (pre-pulse inhibition of acoustic startle; Bubenikova et al. 2005), attention, working memory, long-term memory, executive functions and cognitive coordination (reviewed by Phillips and Silverstein 2003, Keefe and Harvey 2012). Importantly, the cognitive deficits are the most resistant to therapeutic interventions since few (if any) substances are capable of alleviating the cognitive symptoms of this disease 
(Young et al. 2012).

Animal models of brain disorders (reviewed by Jones et al. 2011) are indispensable tools in the study of neuropathological mechanisms of those diseases as well as potential novel therapies (Peleg-Raibstein et al. 2012). Animal models of schizophrenia range from pharmacological manipulations (acute or chronic application of drugs; Jones et al. 2011) to neurodevelopmental (ontogenetic pharmacological, surgical or immunologic manipulations; Wilson and Terry 2010) and a wide variety of genetic models (it should be noted that diverse genetic mutations are interpreted as endophenotypes of schizophrenia (e.g. Willi et al. 2010, reviewed by O'Tuathaigh et al. 2012). Animal models are usually evaluated in terms of validities: face validity reflects phenomenological resemblance of behavioral alterations, construct validity emphasizes common or similar pathogenesis factors or neural substrate of the alterations, and predictive validity evaluates the explanatory value of the model in relation to interventions (the predictive validity most frequently expresses the sensitivity of the animal model to drugs used as therapeutics in humans) (Ellenbroek and Cools 1990).

\section{Cognitive deficits in an animal model of schizophrenia}

Administration of MK-801 (dizocilpine, a high affinity non-competitive NMDA receptor antagonist) to rats and mice produces typical behavioral alterations analogous to selected symptoms of schizophrenia. Moreover, MK-801 and other non-competitive NMDAreceptor antagonist elicit acute psychosis in healthy humans and exacerbate symptoms in schizophrenic patients (Newcomer and Krystal 2011) demonstrating strong face validity of the pharmacological model of schizophrenia by systemic administration of NMDA receptor antagonists. This model is rooted in the glutamatergic hypothesis of schizophrenia. It posits that dysregulation of the glutamatergic neurotransmission is the primary cause of the disease. MK- 801 causes dosedependent hyperlocomotion, social deficit, stereotypies and general behavioral primitivization (Nilsson et al. 2001). Hyperlocomotion in animal models of schizophrenia is considered analogous to positive symptoms in humans and attributed to increased dopaminergic activity in mesolimbic circuits. Importantly, MK-801 (and most NMDA receptor antagonists) also produces a reproducible cognitive deficit and it meets the criteria of a cognition impairer (van der Staay et al. 2011). It impairs inhibitory avoidance, navigation in the Morris water maze (MWM) and object recognition. Our results accumulated over almost 10 years suggested that the acute dose for induction of cognitive deficit in rats of the Long-Evans strain from the breeding colony of the Institute of Physiology in Prague lies between 0.08 and $0.15 \mathrm{mg} / \mathrm{kg}$ (depending on behavioral factors and cognitive demands of the task) and is very close to dose threshold for hyperlocomotion.

Stuchlik et al. (2004) compared the effect of MK-801 $(0.1$ and $0.2 \mathrm{mg} / \mathrm{kg})$ on performance of Long Evans rats in the MWM (Morris et al. 1984, Stuchlik et al. 2007a) with its effect on the place avoidance on Carousel. The lower dose $(0.1 \mathrm{mg} / \mathrm{kg})$ only retarded learning in the MWM, the higher dose $(0.2 \mathrm{mg} / \mathrm{kg})$ severely disrupted performance in both tasks. A profound deficit manifested in the MWM where rats were completely unable to find the escape platform in any of the 60 -s swims. Inability to avoid a place and escape shocks was accompanied by hyperlocomotion in the place avoidance task. A follow-up study (Stuchlik and Vales 2005) examined the effects of two doses of MK-801 on the place avoidance task with pretraining. The lower dose $(0.15 \mathrm{mg} / \mathrm{kg})$ only affected new place avoidance in a new environment, whereas the higher dose $(0.20 \mathrm{mg} / \mathrm{kg})$ also impaired reinforced retrieval in the familiar environment. Dose-dependence study examining the effect of MK-801 $(0.05-0.15 \mathrm{mg} / \mathrm{kg})$ on behavioral flexibility demonstrated the adverse effects of even low doses $(0.08 \mathrm{mg} / \mathrm{kg})$ on reversal learning in both place avoidance on Carousel and Morris water maze (Lobellova et al. 2013). The highest dose $(0.15 \mathrm{mg} / \mathrm{kg})$ also impaired swimming towards visible platform and increased swimming speed. MK-801 $(0.12$ and $0.15 \mathrm{mg} / \mathrm{kg}$ ) also impaired visuospatial working memory and increased locomotion in a modification of the place avoidance task where the location of the to-beavoided place is changed daily (Zemanova et al. 2013), called allothetic place avoidance alternation (Dockery and Wesierska 2010, Dockery et al. 2011). Vales and colleagues (2006) compared the effects of three doses of MK-801 (0.1, 0.2 and $0.3 \mathrm{mg} / \mathrm{kg})$ on place avoidance on Carousel in two outbred strains of rats, Long-Evans and Wistar from the Institute of Physiology breeding colony. In addition, the lowest dose $(0.1 \mathrm{mg} / \mathrm{kg})$ was also tested in a short-term memory version in the MWM with daily changing platform position. Wistar rats proved to be more 
sensitive to the low dose $(0.1 \mathrm{mg} / \mathrm{kg})$ in place avoidance task, but short-term memory in water maze was not disturbed by this dose of MK-801.

The predictive validity of the acute MK-801 animal model was also tested on the Carousel (Bubenikova-Valesova et al. 2008). The place avoidance deficit induced by low dose of MK-801 ( $0.1 \mathrm{mg} / \mathrm{kg})$ was reversed by multi-receptor atypical antipsychotic risperidone and also by ritanserin, an antagonist of 5-HT2A/2C receptors. In contrast, a classical antipsychotic haloperidol did not prevent the place avoidance deficit, but markedly reduced locomotion at higher doses. Interestingly, administration of both antipsychotics alone (without MK-801), but not ritanserin, significantly impaired place avoidance compared to saline-only treated rats (BubenikovaValesova et al. 2008). Vales et al. (2010) investigated the effects modulating glutamatergic neurotransmission by metabotropic glutamate receptor (mGluR) agonists, in search of new therapeutic options for schizophrenia. Agents stimulating mGluR5 such as ACPD ((1S,3R)-1amino-1,3-cyclopentanedicarboxylic acid), DFB (3,3'difluorobenzaldazine) etc. showed beneficial effects, whilst agents acting at mGluR2/3 did not. This finding supports the notion that mGluR represent a promising treatment target (reviewed by Herman et al. 2012). On a similar note, 3alpha5beta-pregnanolone glutamate (PG), a patented neuroprotective steroid derivative, efficiently reversed cognitive deficit induced by MK-801 without affecting locomotion (Vales et al. 2012).

\section{Deficits in spatial navigation and behavioral flexibility in other animal models}

We have recently established an animal model of obsessive-compulsive disorder (OCD) by D2 sensitization by quinpirole in our laboratory (unpublished observations). OCD is a chronic and partly heritable behavioral disorder with strong anxiety component. Its lifetime prevalence is estimated about 1-3\% (Stein 2002). OCD is marked by recurrent intrusive thoughts called obsessions and repetitive uncontrollable behaviors termed compulsions, the latter often reported to neutralize obsessions and reduce anxiety (Stein 2002). OCD negatively affects quality of life and may even completely dominate the life of affected patients. Furthermore, a significant proportion of patients fail to respond to established treatments. The first choice treatments for OCD are selective serotonin re-uptake inhibitors (SSRI) and cognitive-behavioral therapy. A tricyclic antidepressant clomipramine is also used. The pathophysiology of OCD is still unknown. Dysfunction of the fronto-striatal circuits including orbitofrontostriato-thalamic system was associated with the expression of symptoms and the illness. This theory has been revised and newly includes dorsolateral prefrontostriatal system together with the parietal and prefrontal cortices, representing a substantial extension of the proposed circuit (Menzies et al. 2008, Koprivova et al. 2009). Neurochemical abnormalities in OCD affect several neurotransmitter/receptor systems (serotonergic, dopaminergic, glutamatergic, and GABAergic). OCD has been associated with dysfunction of the serotonergic system, based mainly on the responsiveness of the disease to serotonergic drugs such as SSRI and clomipramine. Some evidence pointed to the role of dopamine, based on clinical studies showing benefits of atypical neuroleptics in treatment and on animal model (Szechtman et al. 1994, 1998, 2001). However, recent evidence has emphasized the role of glutamate dysregulation in fronto-striatal systems, including hyperactivity of glutamatergic system in orbitofrontal cortex (OFC), caudate nucleus, and other areas.

The animal model of OCD is based on sensitization of rats with quinpirole, a dopamine D2/D3 receptor agonist. Rats sensitized to quinpirole display behavior in an open-field arena that meets performance criteria for compulsive checking proposed in the literature (Szechtman et al. 1994, 1998, 2001). Indeed, motor rituals after chronic administration of quinpirole resemble several behavioral OCD symptoms to a remarkable extent, which adds to the face validity of this model (Szechtman et al. 1991, 1994, 1998, 2001, Eilam et al. 2005, 2012, Albelda and Joel 2012). Rats chronically treated with quinpirole display a striking preoccupation with one or two places in the arena and return there repeatedly, a pattern of behavior that resembles the spatiotemporal structure of OCD checking (Eilam et al. 2005). This compulsive-like behavior is contextdependent, similarly to OCD patients. Clomipramine (a tricyclic antidepressant commonly used in OCD treatment) attenuates the quinpirole-induced compulsive checking, supporting the predictive validity of this animal model (Szechtman et al. 2001). Construct validity of the model is supported by amelioration of checking behavior by lesions of the orbitofrontal cortex and the nucleus accumbens core (NAc), presumed parts of the OCDcircuit (Dvorkin et al. 2010). This study suggested that 
OFC may support the goal-directed activity (checking of objects, i.e. "focus") while NAc may be responsible for "vigor" of motor performance. Indeed, the quinpirole rat model has been proposed and validated as a useful framework for the conceptualization of human OCD psychopathology in patients (Eilam et al. 2012). Preliminary studies have established this animal model in our laboratory and found no deficit in initial acquisition of place avoidance on the Carousel in quinpirolesensitized animals compared to controls, but revealed significant impairment in reversal learning after relocation of the to-be-avoided place (Hatalova et al., unpublished data).

\section{Drug development}

Searching for novel drugs potentially useful for therapy of CNS damage belongs to most intensively investigated topics in contemporary pharmacology and neuroscience (Fig. 2). Significant advances have been achieved in the field of development and screening of new neuropsychiatric therapeutics based on steroidal compounds naturally occurring in the brain and exerting endogenous neuroprotective activity (Korinek et al. 2011). This research is done in a cooperation of more institutions including Department of Cellular Neurophysiology, Institute of Physiology, Institute of Organic Chemistry and Biochemistry, AS CR, Prague Psychiatric Center etc. An example of such promising compound is PG (see above), a synthetic analogue of pregnanolone sulfate, which is a naturally neuroprotective neurosteroid. The proposed mechanism of its action is blockade of extrasynaptic, tonically-activated NMDA receptors and thereby prevention of excessive glutamate action on neurons. Given these premises, we expect the effect of the designed drugs on normal signal transmission between neurons to be minimal. The role of neurosteroids in the pathogenesis of a number of neuropsychiatric diseases and evaluation of their therapeutic potential has been in focus of biomedical research for the last decade. A number of experimental studies documented their potential in treating several CNS diseases, including neurodegenerative disorders, multiple sclerosis, affective disorders, alcoholism, pain, insomnia, and schizophrenia using animal models (Morrow 2007). The basic goal of this research is obtaining neuroprotective drugs with minimal side effects, i.e. with the most favorable benefit/risk ratio.

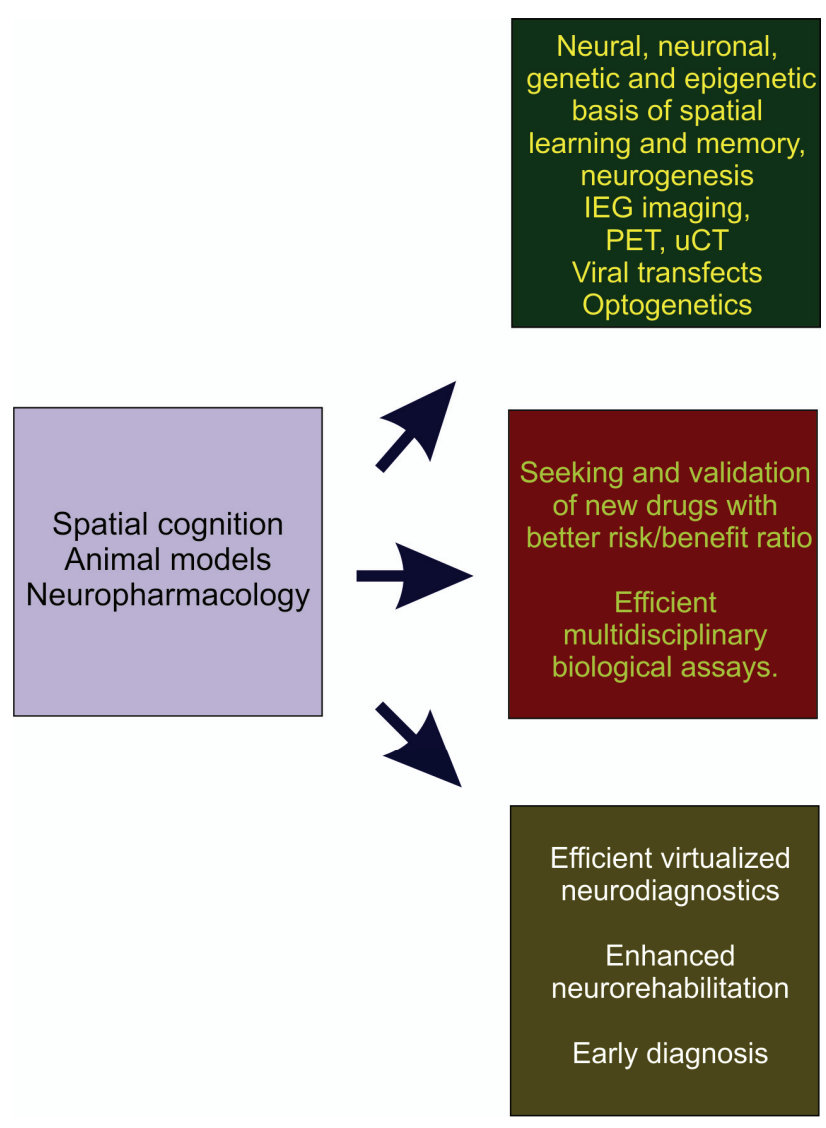

Fig. 2. Outline of future plan of the laboratory. From general interest in spatial cognition, animal models and pharmacology, we continue in three directions: detailed study of brain substrate of cognition, including genetics and epigenetics, neurogenesis and immunohistochemistry, immediate-early gene (IEG) imaging, neuroimaging in whole animals (PET - positron emission tomography, uCT - micro-computed tomography) and viral transfects and optogenetics in the long-term focus. Another direction is seeking and validation of new drugs and efficient assays of biological action of selected substances. The third direction points to more efficient and informative neurodiagnostics, outputs for neurorehabilitation and cognitive training.

PG crosses the blood-brain barrier, preferentially inhibits tonically-activated NMDA receptors, does not induce psychotomimetic symptoms (such as hyperlocomotion and sensorimotor gating deficit), and reduces excitotoxic damage to brain tissue and consequent behavioral impairment in rats. Specifically, PG significantly ameliorated neuronal damage in the dentate gyrus and subiculum and improved place avoidance on the Carousel after bilateral NMDA-induced lesions to the hippocampus (Rambousek et al. 2011). These findings point to therapeutic potential of PG in treating disorders caused by NMDA receptor overactivation (Rambousek et al. 2011). Despite being a use-dependent NMDA receptor antagonist, it also exerts a paradoxical "antipsychotic-like" effect in an animal 
model of schizophrenia by acute systemic MK- 801 . The procognitive properties were evaluated using place avoidance on the Carousel. In addition to the place avoidance behavior, we evaluated effects of PG on locomotor activity and anxiety. PG alone altered neither spatial learning nor locomotor activity in control animals. In the model animals, PG reversed the MK-801-induced cognitive deficit without reducing hyperlocomotion. The highest dose of PG also showed mild but significant anxiolytic properties. Taken together, PG acts to restore normal brain functioning and these results may facilitate development of new drugs to improve cognitive functioning in schizophrenia (Vales et al. 2012).

\section{Spatial navigation deficits in Alzheimer's disease, mild cognitive impairment, and other brain disorders}

Another line of research in our laboratory focuses on alterations in spatial navigation in cognitively impaired patients, mainly due to Alzheimer's disease (AD), schizophrenia, or temporal lobe epilepsy. AD is a neurodegenerative disorder, which affects first and foremost the mediotemporal structures, especially the hippocampus and the parahippocampal gyrus. Episodic memory deficit is a hallmark of the disease, although spatial memory impairment in real space, such as in a hospital lobby, has also been repeatedly reported. A human analogue of the Morris water maze, called Blue Velvet Arena (BVA), has been used in our laboratory for a long time to distinguish allocentric and egocentric spatial deficits. In a Hidden Goal Task in the BVA, the subjects are required to locate either a directly imperceptible goal using two landmarks (allocentric subtest) or their own position (egocentric subtest). We found a deficit in allocentric but not egocentric memory in a group of AD patients using the BVA task, together with a deficit in remembering the presentation order of several locations (as assessed by sequential order in a spatial memory test) (Kalova et al. 2005). In another group of patients we observed impaired spatial navigation in BVA in amnestic patients with single-domain mild cognitive impairment (MCI), presumably due to their memory deficit. Their navigational impairment was limited only to allocentric, but not the egocentric navigation (Hort et al. 2007). This specificity suggests that the critical factor affecting the patients' performance was memory for spatial configurations, rather than visuospatial perceptual functions, which would be required in either test. Impairment of allocentric spatial navigation was found also in the hippocampal subtype of amnestic MCI patients (Laczo et al. 2009) and in amnestic MCI APOE \&4-positive patients (Laczo et al. 2011). Strong correlation between the right hippocampal volume and allocentric navigation efficiency in BVA was found in $\mathrm{MCI}$ and $\mathrm{AD}$ patients using total brain and hippocampal volumetric MRI (Nedelska et al. 2012). This relationship marks the role of the right hippocampus in spatial navigation and likely results from hippocampal atrophy associated with development of AD. Importantly, the link between right hippocampal volume and navigation was observed also in a computerized overhead 2D version of Morris water maze suitable as a clinical diagnostic test for $\mathrm{AD}$.

In parallel, spatial tests in virtual reality environment have been implemented as virtual analogies to real tasks to study spatial cognition independent of locomotion and to facilitate cross-species comparisons (Klement and Bures 2000, Pastalkova et al. 2003, Nekovarova and Klement 2006, Nekovarova et al. 2006a, Klement et al. 2010). These tests were successfully used in rats with reversible inactivations (Levcik et al. 2013a) and pharmacological interventions (Levcik et al. 2013b) as well as in non-human primates and humans (Nekovarova et al. 2006b, 2009, 2013, reviewed in Klement et al. 2008). Virtual tests have significant advantages: the stimuli, timing, and other factors of the experimental design can be easily adjusted; their results can be straightforwardly compared between various animal species and people; and cognitive component can be studied without potentially confounding locomotor (ambulatory) activity. In addition, the virtual test can be used in electrophysiological and in some pharmacological studies where motor functions could be affected and potentially confounding the results.

\section{Conclusions}

The Laboratory of Neurophysiology of Memory has a long-standing interest in learning and memory with special focus on spatial navigation as a model of declarative memory in both healthy and diseased brain. The basic branch of research targets the neuronal and neurochemical mechanisms of navigation in dynamic environments and, using the data from the animal models of disease, this research is translated into development of neuropharmacological in vivo screening, new therapeutic approaches, and novel real and virtual diagnostic tests for patients with neuropsychiatric disorders (Fig. 2). 


\section{Conflict of Interest}

There is no conflict of interest.

\section{Acknowledgements}

This research was supported by GACR PEN center P304/12/G069, GACR P303/12/1464, GACR 14-03627S, by Marie Curie Reintegration grant PIR06-GA/2009256581 from the EU, by IGA MZ CR grants NT13386 and NT13403 and by ASCR project M200111204.
Institutional support was provided by RVO: 67985823 and AV0Z50110509. We thank all students and laboratory assistants for their immense support. We also thank all collaborators from our Institute, Prague Psychiatric Center, Medical Faculties and Faculty of Sciences of Charles University, Hospital Motol, Institute of Organic Chemistry and Biochemistry AS CR and many others including foreign partners.

\section{References}

AIMONE JB, DENG W, GAGE FH: Resolving new memories: a critical look at the dentate gyrus, adult neurogenesis, and pattern separation. Neuron 70: 589-596, 2011.

ALBELDA N, JOEL D: Animal models of obsessive-compulsive disorder: exploring pharmacology and neural substrates. Neurosci Biobehav Rev 36: 47-63, 2012.

ALTMAN J, DAS GD: Autoradiographic and histological evidence of postnatal hippocampal neurogenesis in rats. J Comp Neurol 124: 319-335, 1965.

AMARAL DG, WITTER MP: The tree-dimensional organization of the hippocampal formation: a review of anatomical data. Neuroscience 31: 571-591, 1989.

BANNERMAN DM, RAWLINS JN, MCHUGH SB, DEACON RM, YEE BK, BAST T, ZHANG WN, POTHUIZEN HH, FELDON J: Regional dissociations within the hippocampus-memory and anxiety. Neurosci Biobehav Rev 28: 273-283, 2004.

BANNERMAN DM, BUS T, TAYLOR A, SANDERSON DJ, SCHWARZ I, JENSEN V, HVALBY Ø, RAWLINS JN, SEEBURG PH, SPRENGEL R: Dissecting spatial knowledge from spatial choice by hippocampal NMDA receptor deletion. Nat Neurosci 15: 1153-1159, 2012.

BLAHNA K, SVOBODA J, TELENSKY P, KLEMENT D: Inertial stimuli generated by arena rotation are important for acquisition of the active place avoidance task. Behav Brain Res 216: 207-213, 2011.

BUBENIKOVA V, VOTAVA M, HORACEK J, PALENICEK T, DOCKERY C: The effect of zotepine, risperidone, clozapine and olanzapine on MK-801-disrupted sensorimotor gating. Pharmacol Biochem Behav 80: 591-596, 2005.

BUBENIKOVA-VALESOVA V, STUCHLIK A, SVOBODA J, BURES J, VALES K: Risperidone and ritanserin but not haloperidol block effect of dizocilpine on the active allothetic place avoidance task. Proc Natl Acad Sci USA 105: 1061-1066, 2008.

BUHUSI CV, MECK WH: What makes us tick? Functional and neural mechanisms of interval timing. Nat Rev Neurosci 6: 755-765, 2005.

BURGHARDT NS, PARK EH, HEN R, FENTON AA: Adult-born hippocampal neurons promote cognitive flexibility in mice. Hippocampus 22: 1795-1808, 2012.

BYRNE P, BECKER S, BURGESS N: Remembering the past and imagining the future: a neural model of spatial memory and imagery. Psychol Rev 114: 340-375, 2007.

CHO J, SHARP PE: Head direction, place, and movement correlates for cells in the rat retrosplenial cortex. Behav Neurosci 115: 3-25, 2001.

CZÉH B, STUCHLIK A, WESIERSKA M, CIMADEVILLA JM, POKORNÝ J, SERESS L, BURES J: Effect of neonatal dentate gyrus lesion on allothetic and idiothetic navigation in rats. Neurobiol Learn Mem 75: 190-213, 2001.

DOCKERY CA, WESIERSKA MJ: A spatial paradigm, the allothetic place avoidance alternation task, for testing visuospatial working memory and skill learning in rats. $J$ Neurosci Methods 191: 215-221, 2010. 
DOCKERY CA, LIEBETANZ D, BIRBAUMER N, MALINOWSKA M, WESIERSKA MJ: Cumulative benefits of frontal transcranial direct current stimulation on visuospatial working memory training and skill learning in rats. Neurobiol Learn Mem 96: 452-460, 2011.

DVORKIN A, SILVA C, MCMURRAN T, BISNAIRE L, FOSTER J, SZECHTMAN H: Features of compulsive checking behavior mediated by nucleus accumbens and orbital frontal cortex. Eur J Neurosci 32: 1552-1563, 2010.

EICHENBAUM H: The hippocampus and declarative memory: cognitive mechanisms and neural codes. Behav Brain Res 127: 199-207, 2001.

EILAM D, SZECHTMAN H: Psychostimulant-induced behavior as an animal model of obsessive-compulsive disorder: An ethological approach to the form of compulsive rituals. CNS Spectr 10: 191-202, 2005.

EILAM D, ZOR R, FINEBERG N, HERMESH H: Animal behavior as a conceptual framework for the study of obsessive-compulsive disorder (OCD). Behav Brain Res 231: 289-296, 2012.

ELLENBROEK BA, COOLS AR: Animal models with construct validity for schizophrenia. Behav Pharmacol 1: 469-490, 1990.

ENTLEROVA M, LOBELlOVA V, HATALOVA H, ZEMANOVA A, VALES K, STUCHLIK A: Comparison of Long-Evans and Wistar rats in sensitivity to central cholinergic blockade with scopolamine in two spatial tasks: An active place avoidance and the Morris water maze. Physiol Behav 120: 11-18, 2013.

FYHN M, MOLDEN S, WITTER MP, MOSER EI, MOSER MB: Spatial representation in the entorhinal cortex. Science 305: 1258-1264, 2004.

GARTHE A, BEHR J, KEMPERMANN G: Adult-generated hippocampal neurons allow the flexible use of spatially precise learning strategies. PloS One 4: e5464, 2009.

HAFTING T, FYHN M, MOLDEN S, MOSER MB, MOSER EI: Microstructure of a spatial map in the entorhinal cortex. Nature 436: 801-806, 2005.

HERMAN EJ, BUBSER M, CONN PJ, JONES CK: Metabotropic glutamate receptors for new treatments in schizophrenia. Handb Exp Pharmacol 213: 297-365, 2012.

HORT J, LACZO J, VYHNALEK M, BOJAR M, BURES J, VLCEK K: Spatial navigation deficit in amnestic Mild cognitive impairment. Proc Natl Acad Sci USA 104: 4042-4047, 2007.

JONES CA, WATSON DJ, FONE KC: Animal models of schizophrenia. Br J Pharmacol 164: 1162-1194, 2011.

KALOVA E, VLCEK K, JAROLIMOVA E, BURES J: Allothetic orientation and sequential ordering of places is impaired in early stages of Alzheimer's disease: corresponding results in real space tests and computer tests. Behav Brain Res 159: 175-186, 2005.

KEEFE RS, HARVEY PD: Cognitive impairment in schizophrenia. Handb Exp Pharmacol 213: 11-37, 2012.

KELEMEN E, FENTON AA: Dynamic grouping of hippocampal neural activity during cognitive control of two spatial frames. PLoS Biol 8: e1000403, 2010.

KHEIRBERK MA, DREW LJ, BURGHARDT NS, COSTANTINI DO, TANNENHOLZ L, AHMARI SE, ZENG H, FENTON AA, HEN R: Differential control of learning and anxiety along the dorsoventral axis of the dentate gyrus. Neuron 77: 955-968, 2013.

KLEMENT D, BURES J: Place recognition monitored by location-driven operant responding during passive transport of the rat over a circular trajectory. Proc Natl Acad Sci USA 97: 2946-2951, 2000.

KLEMENT D, PASTALKOVA E, FENTON AA: Tetrodotoxin infusions into the dorsal hippocampus block nonlocomotor place recognition. Hippocampus 15: 460-471, 2005.

KLEMENT D, BLAHNA K, NEKOVAROVA T: Novel behavioral tasks for studying spatial cognition in rats. Physiol Res 57 (Suppl 3): 161-165, 2008.

KLEMENT D, LEVCIK D, DUSKOVA L, NEKOVAROVA T: Spatial task for rats testing position recognition of an object displayed on a computer screen. Behav Brain Res 207: 480-489, 2010.

KOPRIVOVA J, HORÁCEK J, TINTERA J, PRASKO J, RASZKA M, IBRAHIM I, HÖSCHL C: Medial frontal and dorsal cortical morphometric abnormalities are related to obsessive-compulsive disorder. Neurosci Lett 464: 62-66, 2009. 
KORINEK M, KAPRAS V, VYKLICKY V, ADAMUSOVA E, BOROVSKA J, VALES K, STUCHLIK A, HORAK M, CHODOUNSKA H, VYKLICKY L JR: Neurosteroid modulation of N-methyl-D-aspartate receptors: molecular mechanism and behavioral effects. Steroids 76: 1409-1418, 2011.

KUBÍK S, FENTON AA: Behavioral evidence that segregation and representation are dissociable hippocampal functions. J Neurosci 25: 9205-9212, 2005.

KUBÍK S, STUCHLÍK A, FENTON AA: Evidence for hippocampal role in place avoidance other than merely memory storage. Physiol Res 55: 445-452, 2006.

LACZO J, VLCEK K, VYHNALEK M, VAJNEROVA O, ORT M, HOLMEROVA I, TOLAR M, ANDEL R, BOJAR M, HORT J: Spatial navigation testing discriminates two types of amnestic mild cognitive impairment. Behav Brain Res 202: 252-259, 2009.

LACZO J, ANDEL R, VLCEK K, MACOSKA V, VYHNALEK M, TOLAR M, BOJAR M, HORT J: Spatial navigation and APOE in amnestic mild cognitive impairment. Neurodegener Dis 8: 169-177, 2011.

LEVCIK D, NEKOVAROVA T, STUCHLIK A KLEMENT D: Rats use hippocampus to recognize positions of objects located in an inaccessible space. Hippocampus 23: 153-161, 2013a.

LEVCIK D, STUCHLIK A, KLEMENT D: Effect of block of $\alpha 1$-adrenoceptors on overall motor activity but not on spatial cognition in the object-position recognition task. Physiol Res 62: 561-567, $2013 \mathrm{~b}$.

LOBELLOVA V, ENTLEROVA M, SVOJANOVSKA B, HATALOVA H, PROKOPOVA I, PETRASEK T, VALES K, KUBIK S, FAJNEROVA I, STUCHLIK A: Two learning tasks provide evidence for disrupted behavioural flexibility in an animal model of schizophrenia-like behaviour induced by acute MK-801: a dose-response study. Behav Brain Res 246: 55-62, 2013.

MEZNZIES L, CHAMBERLAIN SR, LAIRD AR, THELEN SM, SAHAKIAN BJ, BULLMORE ET: Integrating evidence from neuroimaging and neuropsychological studies of obsessive-compulsive disorder: the orbitofronto-striatal model revisited. Neurosci Biobehav Rev 32: 525-549, 2008.

MORRIS R: Developments of a water-maze procedure for studying spatial learning in the rat. $J$ Neurosci Methods 11: 47-60, 1984.

MORRIS R: Neurobiology of Learning and Memory. PFAFF DW (ed), Neuroscience in the 21st Century, Springer, New York, 2013.

MORRIS RG, FREY U: Hippocampal synaptic plasticity: role in spatial learning or the automatic recording of attended experience? Philos Trans Royal Soc Lond B Biol Sci 352: 1489-1503, 1997.

MORROW AL: Recent developments in the significance and therapeutic relevance of neuroactive steroids-Introduction to the special issue. Pharmacol Ther 116: 1-6, 2007.

NAKASHIBA T, CUSHMAN JD, PELKEY KA, RENAUDINEAU S, BUHL DL, MCHUGH TJ, RODRIGUEZ BARRERA V, CHITTAJALLU R, IWAMOTO KS, MCBAIN CJ, FANSELOW MS, TONEGAWA S: Young dentate granule cells mediate pattern separation, whereas old granule cells facilitate pattern completion. Cell 149: 188-201, 2012.

NEDELSKA Z, ANDEL R, LACZO J, VLCEK K, HORINEK D, LISY J, SHEARDOVA K, BURES J, HORT J: Spatial navigation impairment is proportional to right hippocampal volume. Proc Natl Acad Sci USA 109: 2590-2594, 2012.

NEKOVAROVA T, KLEMENT D: Operant behavior of the rat can be controlled by the configuration of objects in an animated scene displayed on a computer screen. Physiol Res 55: 105-113, 2006.

NEKOVAROVA T, NEDVIDEK J, BURES J: Spatial choices of rats based on abstract visual information: Pattern- or configuration-discrimination? Behav Brain Res 172: 264-271, 2006 .

NEKOVAROVA T, NEDVIDEK J, BURES J: Spatial choices of macaque monkeys based on abstract visual information. Behav Brain Res 174: 93-100, $2006 \mathrm{~b}$.

NEKOVAROVA T, NEDVIDEK J, KLEMENT D, BURES J: Spatial decisions and cognitive strategies of monkeys and humans based on abstract spatial stimuli in rotation test. Proc Natl Acad Sci USA 106: 15478-15482, 2009.

NEKOVAROVA T, NEDVIDEK J, KLEMENT D, ROKYTA R, BURES J: Mental transformations of spatial stimuli in humans and in monkeys: rotation vs. translocation. Behav Brain Res 240: 182-191, 2013.

NEWCOMER JW, KRYSTAL JH: NMDA receptor regulation of memory and behavior in humans. Hippocampus 11: 529-542, 2011. 
NILSSON M, WATERS S, WATERS N, CARLSSON A, CARLSSON ML: A behavioural pattern analysis of hypoglutamatergic mice--effects of four different antipsychotic agents. J Neural Transm 108: 1181-1196, 2001.

O'KEEFE J, DOSTROVSKY J: The hippocampus as a spatial map. Preliminary evidence from unit activity in the freely-moving rat. Brain Res 34: 171-175, 1971.

O’KEEFE J, NADEL L: Hippocampus as a Cognitive Map. Clarendon Press, London, 1978.

O'TUATHAIGH CM, DESBONNET L, WADDINGTON JL: Mutant mouse models in evaluating novel approaches to antipsychotic treatment. Handb Exp Pharmacol 213: 113-145, 2012.

PASTALKOVA E, KELEMEN E, BURES J: Operant behavior can be triggered by the position of the rat relative to objects rotating on an inaccessible platform. Proc Natl Acad Sci USA 100: 2094-2099, 2003.

PELEG-RAIBSTEN D, FELDON J, MEYER U: Behavioral animal models of antipsychotic drug actions. Handb Exp Pharmacol 212: 361-406, 2012.

PETRÁSEK T, STUCHLÍK A: Serotonin-depleted rats are capable of learning in active place avoidance, a spatial task requiring cognitive coordination. Physiol Res 58: 299-303, 2009.

PHILLIPS WA, SILVERSTEIN SM: Convergence of biological and psychological perspectives on cognitive coordination in schizophrenia. Behav Brain Sci 26: 65-82, 2003.

RAMBOUSEK L, BUBENIKOVA-VALESOVA V, KACER P, SYSLOVA K, KENNEY J, HOLULBOVA K, NAJMANOVA V, ZACH P, SVOBODA J, STUCHLIK A, CHODOUNSKA H, KAPRAS V, ADAMUSOVA E, BOROVSKA J, VYKLICKY L, VALES K: Cellular and behavioural effects of a new steroidal inhibitor of the N-methyl-d-aspartate receptor 3 $\alpha 5 \beta$-pregnanolone glutamate. Neuropharmacology 61: 61-68, 2011.

SAHAY A, SCOBIE KN, HILL AS, O'CARROLL CM, KHEIRBEK MA, BURGHARDT NS, FENTON AA, DRANOVSKY A, HEN R: Increasing adult hippocampal neurogenesis is sufficient to improve pattern separation. Nature 472: 466-470, 2011.

SCOVILLE WB, MILNER B: Loss of recent memory after bilateral hippocampal lesions. J Neurol Neurosurg Psychiatry 20: 11-21, 1957.

STEIN DJ: Obsessive-compulsive disorder. Lancet 360: 397-405, 2002.

STUCHLIK A, VALES K: Systemic administration of MK-801, a non-competitive NMDA-receptor antagonist, elicits a behavioural deficit of rats in the Active Allothetic Place Avoidance (AAPA) task irrespectively of their intact spatial pretraining. Behav Brain Res 159: 163-171, 2005.

STUCHLIK A, VALES K: Effect of dopamine D1 receptor antagonist SCH23390 and D1 agonist A77636 on active allothetic place avoidance, a spatial cognition task. Behav Brain Res 172: 250-255, 2006.

STUCHLIK A, VALES K: Role of alpha1- and alpha2-adrenoceptors in the regulation of locomotion and spatial behavior in the active place avoidance task: a dose-response study. Neurosci Lett 433: 235-240, 2008.

STUCHLIK A, VALES K: Baclofen dose-dependently disrupts learning in a place avoidance task requiring cognitive coordination. Physiol Behav 97: 507-511, 2009.

STUCHLIK A, REZACOVA L, VALES K, BUBENIKOVA V, KUBIK S: Application of a novel Active Allothetic Place Avoidance task (AAPA) in testing a pharmacological model of psychosis in rats: comparison with the Morris Water Maze. Neurosci Lett 366: 162-166, 2004.

STUCHLIK A, REHAKOVA L, TELENSKY P, VALES K: Morris water maze learning in Long-Evans rats is differentially affected by blockade of D1-like and D2-like dopamine receptors. Neurosci Lett 422: 169-174, 2007a.

STUCHLIK A, REHAKOVA L, RAMBOUSEK L, SVOBODA J, VALES K: Manipulation of D2 receptors with quinpirole and sulpiride affects locomotor activity before spatial behavior of rats in an active place avoidance task. Neurosci Res 58: 133-139, $2007 \mathrm{~b}$.

STUCHLIK A, PETRASEK T, VALES K: Dopamine D2 receptors and alpha1-adrenoceptors synergistically modulate locomotion and behavior of rats in a place avoidance task. Behav Brain Res 189: 139-144, 2008.

STUCHLIK A, PETRASEK T, HATALOVÁ H, RAMBOUSEK L, NEKOVAROVA T, VALES K: Behavioral tests for evaluation of information processing and cognitive deficits in rodent animal models of neuropsychiatric disorders. In: Schizophrenia in the 21st Century. BURNE THJ (ed), InTech, Rijeka, 2012. 
STUCHLIK A, PETRASEK T, PROKOPOVA I, HOLUBOVA K, HATALOVA H, VALES K, KUBIK S, DOCKERY C, WESIERSKA M: Place avoidance tasks as tools in the behavioral neuroscience of learning and memory. Physiol Res 62 (Suppl 1): S1-S19, 2013.

SVOBODA J, TELENSKY P, BLAHNA K, ZACH P, BURES J, STUCHLIK A: Lesion of posterior parietal cortex in rats does not disrupt place avoidance based on either distal or proximal orienting cues. Neurosci Lett $\mathbf{4 4 5}$ : 73-77, 2008.

SVOBODA J, TELENSKÝ P, BLAHNA K, BUREŠ J, STUCHLÍK A: Comparison of male and female rats in avoidance of a moving object: more thigmotaxis, hypolocomotion and fear-like reactions in females. Physiol Res 61: 659-663, 2012.

SZECHTMAN H, CULVER K, EILAM D: Role of dopamine systems in obsessive-compulsive disorder (OCD): implications from a novel psychostimulant-induced animal model. Pol J Pharmacol 51: 55-61, 1991.

SZECHTMAN H, TALANGBAYAN H, CANARAN G, DAI H, EILAM D: Dynamics of behavioral sensitization induced by the dopamine agonist quinpirole and a proposed central energy control mechanism. Psychopharmacology (Berl) 115: 95-104, 1994.

SZECHTMAN H, SULIS W, EILAM D: Quinpirole induces compulsive checking behavior in rats: a potential animal model of obsessive-compulsive disorder (OCD). Behav Neurosci 112: 1475-1485, 1998.

SZECHTMAN H, ECKERT MJ, TSE WS, BOERSMA JT, BONURA CA, MCCLELLAND JZ, CULVER KE, EILAM D: Compulsive checking behavior of quinpirole-sensitized rats as an animal model of obsessive-compulsive disorder (OCD): form and control. BMC Neurosci 2: 4, 2001.

TAUBE JS, MULLER RU, RANCK JB JR: Head-direction cells recorded from the postsubiculum in freely moving rats. I. Description and quantitative analysis. J Neurosci 10: 420-435, 1990.

TELENSKY P, SVOBODA J, PASTALKOVA E, BLAHNA K, BURES J, STUCHLIK A: Enemy avoidance task: a novel behavioral paradigm for assessing spatial avoidance of a moving subject. $J$ Neurosci Methods $\mathbf{1 8 0}$ : 29-33, 2009.

TELENSKY P, SVOBODA J, BLAHNA K, BURES J, KUBIK S, STUCHLIK A: Functional inactivation of the rat hippocampus disrupts avoidance of a moving object. Proc Natl Acad Sci USA 108: 5414-5418, 2011.

TOLMAN EC: Cognitive maps in rats and men. Psychol Rev 55: 189-208, 1948.

VALES K, STUCHLIK A: Central muscarinic blockade interferes with retrieval and reacquisition of active allothetic place avoidance despite spatial pretraining. Behav Brain Res 161: 238-244, 2005.

VALES K BUBENIKOVA-VALESO V, KLEMENT D, STUCHLIK A: Analysis of sensitivity to MK-801 treatment in a novel active allothetic place avoidance task and in the working memory version of the Morris water maze reveals differences between Long-Evans and Wistar rats. Neurosci Res 55: 383-388, 2006.

VALES K, SVOBODA J, BENKOVICOVA K, BUBENIKOVA-VALESOVA V, STUCHLIK A: The difference in effect of mGlu2/3 and mGlu5 receptor agonists on cognitive impairment induced by MK-801. Eur $J$ Pharmacol 639: 91-98, 2010.

VALES K, RAMBOUSEK L, HOLUBOVA K, SVODODA J BUBENIKOVA-VALESOVA V, CHODOUNSKA H, VYKLICKY L, STUCHLIK A: 3 $\alpha 5 \beta$-Pregnanolone glutamate, a use-dependent NMDA antagonist, reversed spatial learning deficit in an animal model of schizophrenia. Behav Brain Res 235: 82-88, 2012.

VAN DER STAAY FJ, RUTTEN K, ERB C, BLOKLAND A: Effects of the cognition impairer MK-801 on learning and memory in mice and rats. Behav Brain Res 220: 215-229, 2011.

WESIERSKA M, DOCKERY C, FENTON AA: Beyond memory, navigation, and inhibition: behavioral evidence for hippocampus-dependent cognitive coordination in the rat. J Neurosci 25: 2413-2419, 2005.

WESIERSKA M, ADAMSKA I, MALINOWSKA M: Retrosplenial cortex lesion affected segregation of spatial information in place avoidance task in the rat. Neurobiol Learn Mem 91: 41-49, 2009.

WHITLOCK JR, PFUHL G, DAGSLOTT N, MOSER MB, MOSER EI: Functional split between parietal and entorhinal cortices in the rat. Neuron 73: 789-802, 2012.

WILLI R, WEINMANN O, WINTER C, KLEIN J, SOHR R, SCHNELL L, YEE BL, FELDON J, SCHWAB ME: Constitutive genetic deletion of the growth regulator Nogo-A induces schizophrenia-related endophenotypes. J Neurosci 30: 556-567, 2010. 
WILSON C, TERRY AV JR: Neurodevelopmental animal models of schizophrenia: role in novel drug discovery and development. Clin Schizophr Relat Psychoses 4: 124-137, 2010.

WINOCUR G BECKER S, LUU P, ROSENQWEIG S WOJTOWICZ: Adult hippocampal neurogenesis and memory interference. Behav Brain Res 227: 464-469, 2011.

WISKOTT L, RASCH MJ, KEMPERMANN G: A functional hypothesis for adult hippocampal neurogenesis: avoidance of catastrophic interference in the dentate gyrus. Hippocampus 16: 329-343, 2006.

YOUNG JW, AMITAI N, GEYER MA: Behavioral animal models to assess pro-cognitive treatments for schizophrenia. Handb Exp Pharmacol 213: 39-79, 2012.

ZEMANOVA A, STANKOVA A, LOBELLOVA V, SVOBODA J, VALES K, VLCEK K, KUBIK S, FAJNEROVA I, STUCHLIK A: Visuospatial working memory is impaired in an animal model of schizophrenia induced by acute MK-801: An effect of pretraining. Pharmacol Biochem Behav 106: 117-123, 2013. 